\title{
Educação profissional: a importância do curso de formação profissional na qualidade dos serviços na área da segurança pública
}

\author{
Professional education: the importance of the professional training course in the quality of services \\ in the area of public security
}

Educación profesional: la importancia del curso de formación profesional en la calidad de los servicios en el área de seguridad pública

\section{Resumo}

A polícia civil é o setor da administração pública oficialmente responsável pelo exercício do controle social e pela garantia da Segurança Pública. O Curso de Formação para Policiais Civis, teve como objetivo qualificar profissionalmente policiais para atuar em diferentes setores da polícia civil do Estado da Paraíba. Enquanto metodologia utilizou-se aulas expositivo-dialogadas; exibição de vídeos e filmes para debates em sala, rodas de conversas, bem como discussão de textos e apresentações de seminários. Os resultados sinalizam que o atendimento ao público é um serviço de grande complexidade; trata-se de uma atividade social mediadora, visando responder a diferentes necessidades. É imprescindível ter comprometimento com o trabalho que realizamos, zelar pela imagem da instituição que trabalhamos e, sobretudo, respeitar o cidadão independente da sua raça, classe social, etnia e gênero. Por tudo isso, sinaliza-se para a necessidade de uma formação profissional continuada, abarcando diferentes disciplinas, tais como Qualidade no Atendimento, de acordo com a Grade Curricular Nacional no âmbito da Segurança Pública.

Palavras-chave: Segurança pública; Polícia civil; Educação profissional; Qualidade no atendimento.

\begin{abstract}
The civil police is the sector of public administration officially responsible for exercising social control and guaranteeing Public Security. The Civil Police Training Course aimed to professionally qualify police officers to work in different sectors of the civil police in the State of Paraíba. As a methodology, expository-dialogued classes were used; exhibition of videos and films for classroom debates, conversation circles, as well as discussion of texts and seminar presentations. The results indicate that customer service is a highly complex service; it is a mediating social activity, aiming to respond to different needs. It is essential to be committed to the work we do, to care for the image of the institution we work for and, above all, to respect citizens regardless of their race, social class, ethnicity and gender. For all these reasons, there is a need for continued professional training, covering different disciplines, such as Quality of Service, according to the National Curriculum Framework within the scope of Brazilian Public Security.
\end{abstract}

Keywords: Public security; Civil police; Professional education; Quality of service.

\section{Resumen}

La policía civil es el sector de la administración pública oficialmente encargado de ejercer el control social y garantizar la Seguridad Pública. El Curso de Formación de Policía Civil tuvo como objetivo capacitar profesionalmente a los policías para actuar en diferentes sectores de la policía civil en el Estado de Paraíba. Como metodología se utilizaron clases expositivas-dialogadas; exhibición de videos y películas para debates en el aula, círculos de conversación, asî como discusión de textos y presentaciones de seminarios. Los resultados indican que la atención al cliente es un servicio de alta complejidad; es una actividad social mediadora, que pretende dar respuesta a diferentes necesidades. Es fundamental estar comprometidos con el trabajo que hacemos, cuidar la imagen de la institución para la que trabajamos y, sobre todo, respetar a los ciudadanos sin importar su raza, clase social, etnia y género. Por todas estas razones, existe la necesidad de una formación profesional continua, que abarque diferentes disciplinas, como la Calidad de Servicio, de acuerdo con el Marco Curricular Nacional en el ámbito de la Seguridad Pública brasileña.

Palabras clave: Seguridad pública; Policía civil; Educación profesional; Calidad de servicio. 


\section{Introdução}

O campo de atuação da polícia civil no Estado da Paraíba está dividido por áreas de policiamento: Capital e região metropolitana e todos os 223 municípios paraibanos. As funções da polícia além de repressivas e ostensiva são também de efeito preventivo. São competências dos policiais: investigar delitos e encaminhar resultados da investigação à justiça comum estadual; instaurar inquéritos policiais; autuar em flagrante; efetuar prisão preventiva e temporária; efetuar buscas e apreensões mediante ordem judicial; realizar perícias e exames de corpo delito.

Este estudo faz parte da disciplina qualidade no atendimento na segurança pública, ministrada para todos os aprovados em concurso público e nomeados, sendo tal disciplina requisito para assumir o cargo, portanto os nomeados devem obrigatoriamente realizar o curso de formação, para que possam desenvolver habilidades e competências, além de capacitá-los de acordo com a função que irão exercer. De acordo com Miranda (2008) para romper os paradigmas vigentes do ensino policial e estabelecer outros conceitos é preciso compreender quais são as limitações existentes. Para construir uma formação que valorize o respeito aos direitos dos cidadãos, base de qualquer democracia, é fundamental compreender que a cidadania não se constrói apenas com a mudança da legislação e, sim, com a mudança de práticas. No caso brasileiro, para romper o modelo vigente, a polícia no Brasil precisaria deixar de servir prioritariamente ao Estado, para se tornar a instituição que presta serviços de qualidade à sociedade.

As instalações e toda estrutura pedagógica disponibilizada pela Acadepol tem o propósito de incentivar os policiais a buscarem o seu potencial e serem avaliados em suas deficiências para o alcance da excelência na prestação dos serviços. Tratase de um ambiente propício para promover o encontro dos policiais de todas as regiões do estado da Paraíba e, assim, facilitar o debate e a troca de experiências, construindo uma instituição verdadeiramente conhecedora de suas demandas. A Academia de Polícia do Estado da Paraíba adota um modelo de educação teórico-prático que abrange as várias áreas de ação da segurança pública e da defesa social. Os policiais podem escolher diferentes cursos conforme sua vocação, preferência ou área de atuação (Acadepol, 2022).

A violência policial com aumento no índice de mortes é um problema de saúde pública. Para além dos assustadores índices de homicídio no Brasil, ocorre também o crescimento da violência policial letal, como aponta os estudos de Ryngelblum e Peres (2021). De acordo com o Anuário Brasileiro de Segurança Pública (2019), no ano de 2018, 6.220 pessoas foram mortas pela polícia, representando $10 \%$ de todas as mortes violentas intencionais neste ano. Ryngelblum e Peres (2021) sinalizam que o ano de 2020 evidenciou, como nunca antes, a brutalidade policial, com o caso George Floyd e sua repercursão mundial. Centenas de cidades pelo mundo foram ocupadas pela população, exigindo justiça e equidade racial sob a bandeira do Black Lives Matter. Ainda, em 2020, a crise da COVID-19 destacou a importância da produção de dados em saúde, que se tornou objeto de controvérsia pública, com suas imprecisões e disputas de versões.

Neste sentido, percebe-se cada vez mais a importância de uma formação profissional continuada, uma educação permanente, com o intuito de capacitar e qualificar policiais para atuar em diferentes contextos e situações na área da segurança pública, com a adoção da Matriz Curricular Nacional pela Secretaria Nacional de Segurança Pública, com a indicação de que todas as escolas de formação das forças policiais dos Estados membros da federação adotassem suas diretrizes. Nessa linha de estudos sobre a formação profissional de policiais, destacam-se as pesquisas acadêmicas de Poncioni (2005), Miranda (2008) e Basilio (2010), Spaniol e Rodrigues (2018), dentre outros.

Durante os meses de outubro de 2010 a março de 2011, por um período de seis meses, os 450 concursados para a área de segurança pública do Estado da Paraíba, concluíram o curso de formação para policiais civis, na Academia de Polícia da Paraíba (Acadepol/PB) estando até os dias atuais exercendo suas atividades. O curso de formação, tem como principal objetivo qualificar policiais civis para atuar em diferentes áreas da polícia civil do Estado da Paraíba. 
A Polícia Civil do Estado da Paraíba, dirigida pelo Delegado Geral de Polícia Civil, desenvolve os serviços públicos da sua competência, basicamente, através das delegacias policiais. As delegacias distribuídas pelo território estadual, são, nas suas circunscrições, o centro das investigações e dos demais atos de polícia judiciária e pontos de atendimento e proteção à população. O Estado está dividido em 10 regiões de Polícia Civil, uma metropolitana e outras em Campina Grande, Guarabira, Monteiro, Patos, Itaporanga, Cuité, Catolé do Rocha, Cajazeiras e Itabaiana (Sindspol/PB, 2022).

É neste contexto referente ao perfil dos profissionais que atuam nos mais diversos órgãos da segurança pública brasileira, percebe-se uma visível tendência de mudança, na procura por qualificação a partir do seu ingresso no cargo, observase nestas instituições a exigência da formação superior para concorrer a uma vaga nas carreiras policiais e, algumas instituições, como é o caso das polícias militares de muitos Estados da federação passaram a exigir a formação jurídica para os seus novos quadros de oficiais, nos moldes como já era exigido aos delegados da polícia civil (Spaniol \& Rodrigues, 2018).

Há estudiosos que apontam uma carência no modelo antigo de formação científicos que venham facilitar e melhorar o trato com a sociedade. Nesta visão sobre formação e recrutamento, Detoni (2014) sinaliza alguns avanços, mas os sinais de uma formação centrada em modelos tradicionais e opressores, ainda existem, havendo pouco espaço para uma formação mais ampla e aprofundada sobre a especificidade da profissão policial, o contexto de ação, a complexidade social, as exigências psicológicas e éticas para o exercício adequado diante das demandas da sociedade.

Neste sentido, compreende-se que a formação dos policiais brasileiros necessita de ajustes e adaptações para que sejam profissionais especializados capazes de empreender essa atividade necessária de maneira mais eficaz, respondendo, com eficiência e prontidão, ao anseio social por maior segurança pública.

Por tudo isso, faz-se necessário uma qualificação profissional permanente, que aborde diferentes aspectos, tanto com relação à prática profissional quanto a fundamentos éticos e teóricos que dê sustentação à práxis. Neste sentido, o curso de formação para policiais civis, tem como objetivo qualificar profissionalmente policiais para atuar em diferentes setores da polícia civil do Estado da Paraíba.

\section{Metodologia}

Este artigo consiste em um relato de experiência na área da Segurança Pública no Estado da Paraíba, através do uso de metodologias ativas e participativas e abordagem de cunho qualitativa, por meio de análise categorial temática proposta por Minayo (2010).

Por meio de um método dialético (Estrela, 2018), de abordagem qualitativa (Minayo, 2010), que ressaltam a necessidade de uma análise crítica da realidade, para que se possa compreender e intervir sobre ela, considera-se que os fatos não podem ser observados fora de um contexto social; as contradições se transcendem dando origem a novas contradições que requerem soluções, através de sua ação recíproca, da contradição inerente ao fenômeno e da mudança dialética que ocorre na natureza e na sociedade (Pereira, 2018).

Portanto, o aporte metodológico abordado no programa de formação alinhado ao processo de ensino e aprendizagem fez uso de diferentes metodologias, tais como: discussão e análises de textos, estudo de caso, apresentação de seminários, rodas de conversa, relatos e palestras na sala de aula com profissionais atuantes na área de segurança pública, contribuindo assim para ampliar os saberes.

Foram seguidos, rigorosamente, os princípios norteadores elencados na Matriz Curricular Nacional. Faz-se necessário destacar os princípios norteadores inseridos na Matriz Curricular Nacional, de acordo com Brasil (2014), são definidos como preceitos que fundamentaram a concepção das ações formativas para os profissionais da área de segurança pública e são classificados em três grupos: ético, educacional e didático-pedagógico. 
No que se refere aos princípios educacional e didático-pedagógicos, há uma necessidade de se buscar constantes atualizações com novos aportes científicos, pesquisas, diagnósticos e conhecimentos. Esses princípios, de acordo com Nascimento (2013), devem fazer parte dos cursos de formação de policiais, abrangendo as ações e atividades do processo de planejamento, execução e avaliação conforme descrito nos princípios da Matriz Curricular Nacional.

Ao ter como pressupostos a Grade Curricular Nacional do Ministério da Justiça (Brasil, 2009), a área da segurança pública do Estado da Paraíba, realizou com os 450 concursados das diferentes categorias profissionais da polícia civil, um curso de formação profissional, durante os meses de outubro de 2010 a março de 2011, por um período de 06 (seis) meses. Participaram diversos cargos: Agentes de Investigação; Delegados/as; Escrivães; Necrotomistas; Perito/a Oficial Criminal; Perito/a Médico/a Legal; Perito/a Oficial Odonto Legal; Perito/a Oficial Químico/a Legal e Técnicos/as em Perícia.

\section{Resultados e Discussão}

Os resultados alcançados neste curso de formação devem-se, principalmente, com relação à abordagem metodológica utilizada, contribuiu na mobilização dos saberes acumulados pelos profissionais envolvidos, possibilitando-os a reconhecer a importância de suas experiências para a transformação das situações de trabalho e do atendimento ao público. Dessa maneira, foram abordados no curso de formação diferentes temáticas: qualidade no atendimento, condições e organização do trabalho, cultura e clima organizacional, liderança, saúde mental e subjetividades, vulnerabilidades e saúde mental. Por outro lado, os estudos de caso, os documentários e filmes assistidos e discussão nos encontros em sala de aula, possibilitaram o engajamento dos participantes, o aprofundamento das análises e a amplitude dessa proposta.

Verificou-se que os policiais participantes do curso eram jovens, com faixa etária entre 20 e 48 anos de idade, possuíam formação superior nas mais diversas áreas, contribuindo assim para uma aprendizagem satisfatória e bastante significativa, valorizando o conhecimento peculiar de cada servidor, através da troca de experiências e saberes, por meio de uma aprendizagem reflexiva, enriquecedora e crítica, mobilizando para a construção de uma visão ampla sobre segurança pública e práticas transformadoras que buscam melhorias para a sociedade paraibana e diminuição dos índices de violência e criminalidade.

$\mathrm{O}$ aspecto relevante dessa Formação foi constatado pelo interesse vivenciado pelos participantes e suas valiosas descobertas acerca das relações que se estabelecem entre os processos de trabalho que se desenvolvem na polícia civil, a melhoria no atendimento ao público, as relações interpessoais e a comunicação interna. Os estudos de Souza e Minayo (2017) apontam que cabe as polícias a missão "quase impossível" de prevenir os crimes e as infrações, investigar os delitos e proteger a sociedade. Contudo, elas estão encurraladas entre a crescente violência de grupos organizados e bem equipados e suas precárias condições de trabalho para fazer-lhes frente. O problema não é o de apenas fornecer-lhes mais armas e viaturas, mas sim, o de oferecerlhes treinamento de excelência e adequado, apoio para o trabalho diário em áreas conflagradas onde, não raramente, perdem seus companheiros e têm que virar o turno, sem amparo emocional e sem descanso.

Outro resultado importante do programa de formação foi que na trama do dispositivo se teceu um tipo de sociabilidade que reuniu horizontalmente, sem excluir as diferenças inerentes a cada segmento, entre diversas categorias profissionais. No decorrer do curso foram aprendendo uns com os outros a compartilharem suas vivências, suas diferenças, seus sofrimentos, convivendo no mesmo espaço, tendo acesso às mesmas informações, realizando os exercícios de estudo de campo conjuntamente, enfim, dialogando e confrontando suas experiências. Este compartilhamento evidenciou a diversidade de opiniões, de olhares, de concepções acerca dos problemas do mundo do trabalho.

Tal situação mostra os problemas e as dificuldades dos diferentes sujeitos, cujas origens estão em outras instâncias ou momentos, por exemplo, na falta de treinamento do servidor, na desinformação do cidadão/usuário ou no planejamento ineficaz da Instituição. Os problemas existentes no atendimento ao público se manifestam por intermédio de diferentes indicadores. Dentro de uma instituição é muito importante a manutenção de programas de qualidade, mas, para isso é preciso projetos e 
gerenciamento. Nos vários momentos de avaliação da experiência, os/as profissionais colocaram a importância do Curso de Formação nas suas vidas e no seu trabalho, enfatizando a riqueza de informações e do conhecimento que adquiriram. Eles/as colocaram ainda que através deste puderam refletir e discutir melhor sobre o ambiente de trabalho, a importância política e a capacidade de mudança a partir de uma visão mais crítica da realidade que estão inseridos/as.

As instituições que prestam serviço na área de Segurança Pública necessitam de profissionais com um perfil diferenciado, mais dinâmico, flexível e com criatividade para enfrentar e solucionar problemas (Gama, 2008, p.2). O atendimento diferenciado, sobretudo em órgãos públicos, com o objetivo para que a população se sinta acolhida e compreenda que está realmente em um local que irá resolver seus problemas e ajudar a resolver seus conflitos.

Vale destacar, também, para a sobrecarga de trabalho vivenciada pelos policiais, o elevado nível de estresse que sofrem diariamente nos locais de trabalho, seus corpos estão expostos aos mais diversos tipos de riscos, onde estão o tempo todo colocando as suas vidas em risco, pois o perigo e as precárias condições laborais são inerentes aos atributos de suas atividades. Deve-se investir em cursos sobre a promoção da saúde nos locais de trabalho, relacionamento interpessoal, subjetividade e saúde mental, melhorar o aparato organizacional e as condições de trabalho, a estrutura física e instrumental são essenciais, pois as pessoas devem ser levadas em consideração para a compreensão do que se passa no ambiente de trabalho do servidor. Por tudo isso, a segurança pública apresenta-se como um desafio institucional que parece exigir transformações urgentes.

Para a efetivação da formação profissional pretendida, Luiz (2003) afirma que as instituições de ensino "precisam planejar as ações educativas a partir da análise crítica de suas ações pedagógicas e de sua missão organizacional, das divergências verificadas em relação a problemática do mundo profissional e sociocultural".

A sociedade precisa participar de maneira ativa, sobre este aspecto Brasil, Miranda e Cruz (2015), apontam que ao instigar a participação da sociedade nas políticas públicas de segurança centradas em ações preventivas e de redução da violência, para a modernização e democratização do circuito criminal brasileiro, a concepção de segurança pública evidência uma abrangência que vai muito além da relação da polícia com a comunidade.

É notório que o ser humano vive em constante processo de aprendizagem por influência do seu convívio social, adaptando-se às normas e aos valores sociais. A educação profissional continuada é um diferencial para qualquer profissão, sobretudo para as organizações que lidam diretamente com a garantia dos bens jurídicos considerados os mais relevantes - a vida e a liberdade (Azevedo \& Silva, 2018).

De acordo com Poncioni (2005) no Brasil, um panorama, ainda que superficial, da questão da segurança pública mostra que, pelo menos desde meados dos anos 70, há um crescimento contínuo da criminalidade e da violência, principalmente nas regiões metropolitanas e periferias das grandes cidades do país, e que o sistema judiciário, e, em particular, a polícia tem se mostrado ineficaz para o enfrentamento da questão. Notadamente nas áreas urbanas do país, a sensação de medo e insegurança tem sido experimentada como um grave problema público devido à expectativa de que qualquer pessoa pode se tornar vítima de crime em qualquer ponto das cidades e em qualquer momento de sua vida cotidiana.

Neste cenário caótico de insegurança, um dos temas frequentemente levantados por estudiosos da área de segurança, por formuladores de políticas públicas, por autoridades de governo e pelos próprios policiais é a necessidade de profissionalizar a polícia brasileira como um recurso para capacitá-la para o desempenho mais eficiente, mais responsável e mais efetivo na condução da ordem e segurança públicas.

\section{Considerações Finais}

Verifica-se que os achados neste artigo não se encerra aqui, como proposta futura, maiores aprofundamentos podem ser realizados. Pretende-se com o presente estudo ampliar as discussões na área da segurança pública sobre a formação profissional 
de policias civis, contribuindo de forma reflexiva e crítica, propondo melhorias e avanços significativos no atendimento ao público e na qualificação e formação profissional.

Portanto, sabe-se que para mudar o cenário atual de violência, criminalidade e insegurança não é unicamente exclusivo das polícias e guardas municipais, envolve um aparato de iniciativas e comprometimento de governos e de toda a sociedade civil. A constante educação voltada ao policial é imprescindível para atender as demandas da população de forma satisfatória, além de reduzir a ocorrência de arbitrariedades e erros profissionais, com resultados inadequados, comprometendo a credibilidade e confiabilidade na instituição da polícia civil.

\section{Referências}

Acadepol. Academia de Polícia da Paraíba. (2022). https://acadepolpb.webnode.com

Azevedo, P. P. M., \& Siva, V. C. (2018). Educação profissional continuada - implementação do calendário anual de cursos na polícia militar de Tocantins. Aturá Revista Pan-Amazônica de Comunicação, Palmas, 2(3), 163-183. file://C:/Users/edila/Downloads/5964-Texto\%20do\%20artigo-27996-1-10-20180930.pdf

Basilio, M. P. (2010). O desafio da formação do Policial Militar do Estado do Rio de Janeiro: entre o modelo reativo e o contingencial. Administración y Desarrollo, 38(52), 71-96. https://dialnet.unirioja.es/servlet/articulo?codigo=3731155

Brasil. (2009). Ministério da Justiça. Secretaria Nacional de Segurança Pública. Matriz Curricular Nacional para a formação em Segurança Pública Versão Modificada e Ampliada, Brasília: SENASP, (2a ed.). http://mj.gov.br

Brasil. (2014). Ministério da Justiça. Secretaria Nacional de Segurança Pública. Matriz Curricular Nacional para ações formativas dos profissionais da área de segurança pública. Brasília: SENASP, (3a ed.). https://dspace.mj.gov.br/handle/1/2320

Brasil, G. M., Miranda, A. K. P. C. \& Cruz, L. A. (2015). A Segurança Pública e a Política Brasileira de Formação Policial, Em G.M. Brasil., R.O Almeida \& G.J. Freitas (Orgs.), Formação Policial: Experiências e práticas de policiamento. Pontes Editores, p. 53-116.

Detoni, M. P. (2014). Formação Policial: Contribuições Pedagógico-Filosóficas. CRV.

Estrela, C. (2018). Metodologia Científica: Ciência, Ensino, Pesquisa. Editora Artes Médicas.

Fórum Brasileiro de Segurança Pública. (2019). Anuário de Brasileiro de Segurança de

» https://forumseguranca.org.br/wp-content/uploads/2019/10/Anuario-2019-FINAL_21.10.19.pdf

Gama, A. (2008). Qualidade no Atendimento/Academia de Polícia Civil, Brasília.

Luiz, R. S. (2003). O Currículo de Formação de Soldados da Polícia Militar Frente às Demandas Democráticas. Dissertação (Mestrado em Educação). Pontifícia Universidade Católica de São Paulo - PUC/SP.

Minayo, M. C. S. (2010). O desafio do conhecimento: pesquisa qualitativa em saúde. (12a ed.). Hucitec.

Minayo, M. C. S. \& Souza, E. R. (2003). Missão investigar: entre o ideal e a realidade de ser policial. Garamond.

Minayo, M.C.S., Souza, E. R. \& Constantino, P. (2007). Riscos percebidos e vitimação de policiais civis e militares na (in) segurança pública. Cad. Saúde Pública, Rio de Janeiro, 23(11):2767-2779.

Miranda, A. P. M. (2008). Dilemas da formação policial: treinamento, profissionalização e mediação. Educação profissional: ciência e tecnologia, 3(1). https://app.uff.br/riuff/bitstream/handle/1/6107/Dilemas_da_formacao_policial_treinamento.pdf?sequence=1\&isAllowed=y

Nascimento, D. A. (2013). Concepções da Educação Policial: O que pensam os professores? CRV.

Pereira, A.S. (2018). Metodologia da pesquisa científica. UFSM.

Poncioni, P. (2005). O modelo policial profissional e a formação profissional do futuro policial nas academias de polícia do estado do rio de janeiro. Soc. estado. 20 (3). https://doi.org/10.1590/S0102-69922005000300005

Ryngelblum, M. \& Peres, M. F. T. (2021). Análise da qualidade dos dados das mortes cometidas por policiais no município de São Paulo, Brasil, 2014-2015. Cad. Saúde Pública 37(10). https://doi.org/10.1590/0102-311X00317020

Sindspol, Sindicato dos Servidores da Polícia Civil do Estado da Paraíba. (2022). https://sspcpb.com.br/

Souza, E. R. \& Minayo, M. C. S. (2005). Policial, risco como profissão: morbimortalidade vinculada ao trabalho. Ciência \& Saúde Coletiva, 10(4): 917-928.

Souza, E. R. \& Minayo, M. C. S. (2017). Segurança Pública num país violento. Cadernos de Saúde Pública, 33(3). http://dx.doi.org/10.1590/0102$311 \times 00036217$

Spaniol, M. I. \& Rodrigues, C. R. G. (2018). Formação policial contemporânea: avanços e desafios da segurança pública para aliar saberes, práticas e atuação em democracia. Anais do $9^{\circ}$ Congresso internacional de ciências criminais da PUCRS. https://editora.pucrs.br/edipucrs/acessolivre/anais/congressointernacional-de-ciencias criminais/assets/edicoes/2018/comp-list-docs.html 